\title{
Multi-Terrain Earth Landing Systems Applicable for Manned Space Capsules
}

\author{
Edwin L. Fasanella \\ NASA Langley Research Center \\ Edwin.L.Fasanella@nasa.gov
}

\begin{abstract}
A key element of the President's Vision for Space Exploration is the development of a new space transportation system to replace Shuttle that will enable manned exploration of the moon, Mars, and beyond. NASA has tasked the Constellation Program with the development of this architecture, which includes the Ares launch vehicle and Orion manned spacecraft. The Orion spacecraft must carry six astronauts and its primary structure should be reusable, if practical. These requirements led the Constellation Program to consider a baseline land landing on return to earth. To assess the landing system options for Orion, a review of current operational parachute landing systems such as those used for the F-111 escape module and the Soyuz is performed. In particular, landing systems with airbags and retrorockets that would enable reusability of the Orion capsule are investigated. In addition, Apollo tests and analyses conducted in the 1960's for both water and land landings are reviewed. Finally, tests and dynamic finite element simulations to understand land landings for the Orion spacecraft are also presented.
\end{abstract}

\section{Introduction}

After retiring the Space Shuttle in 2010, NASA plans to replace the Space Shuttle orbiter with the Orion spacecraft, a capsule that is larger than the Apollo command module with room for up to six astronauts. Orion will be boosted into orbit by an Ares 1 rocket that will use the Space Shuttle Solid Rocket Booster (SRB). The Orion capsule will service the International Space Station (ISS), and later versions are planned to travel to the moon and then on to Mars. On return from space, the Orion capsule will descend to earth suspended from a parachute. Weight constraints are steering the current Orion design towards water landings, but the design goal is for the Orion crew to "walk away" from land landings due to a pad abort or for any other nominal land landing. Landing site terrain is highly variable, with very hard soil at sites such as the dry-lake beds in California near NASA Dryden and very soft soil at sites such as Carson Sink, Nevada. For a pad or ascent abort from NASA Kennedy Space Center, water is the preferred impact surface, but if the capsule blows back onto land, the impact surface can vary from extremely soft dry sand to hard prepared surfaces. Consequently, landing systems for Orion must be designed for multi-terrain impacts.

For a survivable landing, the velocity of a manned vehicle returning from space must be reduced from approximately $18,000 \mathrm{mph}$ for an earth orbit to a landing sink rate of just a few feet per second. This deceleration can be accomplished using a combination of several different technologies, which may include parachutes, airbags, crushable 
structures and retrorockets. Parachutes were used on Apollo and Soyuz, while airbags have been used on Mars missions, the F-111 fighter jet, and some helicopters. Soyuz also used retrorockets. This paper will present a survey of all of these previously flown landing system technologies and will extract lessons applicable for Orion.

In terms of new landing system work, from 2005 - 2007 NASA's Orion Landing System (LS) Advanced Development Program (ADP) investigated several energy absorbing systems for land landing, including base-mounted retrorocket systems (St.Vaughan, 2007). Concurrently, the ADP began swing testing of full-scale airbag systems on Orion boilerplate test articles at the NASA Langley Landing and Impact Research (LandIR) facility. The airbags are in pairs with a vented main bag for energy absorption and an inner anti-bottoming airbag to prevent ground contact. Although airbag systems with anti-bottoming airbags are somewhat heavier than retrorocket landing systems, airbag systems can both prevent the structure from contacting the impact surface and reduce the impact loads during a land landing. This paper will present representative test data generated at LandIR of developmental airbag landing systems for the Orion capsule. Simulations of airbag systems onto soft soil and of space capsules into water using the nonlinear dynamic finite element code LS-DYNA (Hallquist, 2006) will also be presented and discussed. The goal of landing system research is to develop concepts to attenuate impact loads transmitted to the crew to noninjurious levels. Consequently, human tolerance to impact will be discussed in the next section.

\section{Human Tolerance to Impact}

In order to design a viable Orion landing system, the limits on occupant accelerations must be understood. The accelerations on the seat and occupant in an impact are measured in local X, Y, and Z-directions. For an upright seated occupant such as a passenger in a car, the $\mathrm{X}$-axis is horizontal, $\mathrm{Z}$ is positive upward, and $\mathrm{Y}$ is to the side. Since astronauts are lying on their backs in a supine position, the rearward impact force for a flat capsule impact is in the X-direction perpendicular to the spine and is distributed over a large area. To specify the occupant local axis system in terms of the occupant's body, the $+X$-direction is also called an "eyeballs-in" direction. The "eyeballs" move in the direction opposite to the acceleration vector similar to a bubble in an accelerated liquid. Colonel John Stapp, a pioneer who rode rocket sleds to determine human tolerance, sustained peak accelerations over $46 \mathrm{G}$ 's for frontal accelerations (-Xdirection, eyeballs out) in the early 1950's without sustaining permanent injuries. Colonel Stapp was in an upright seated position. Obviously, an occupant must be well restrained to survive such an impact. For acceleration along the spine, the tolerance is much lower. For example, an acceleration of $20 \mathrm{G}$ 's for 0.1 second is the level experienced by crew in ejection seats. From operational experience and human tolerance studies, it is known that any sustained acceleration of $20 \mathrm{G}$ 's or more along the spine can produce serious injuries including cracked vertebra (Eiband, 1959).

Various models of the seated occupant have been developed including the Dynamic Response Index (DRI), commonly called the Brinkley index after its developer (Brinkley and Moser, 1989). Brinkley lowered the dynamic response limits for NASA to include 
debilitated astronauts (very low). The limits used by the Constellation program for Orion nominal and off nominal landings are shown in Table 1, while the limits from Brinkley and Moser (1989) are given in Table 2. Note that the dynamic response (DR) levels (low, moderate, and high risk) correspond to an injury risk of about $0.5 \%, 5 \%$, and $50 \%$, respectively. Operational spinal injury rate for ejections from various military aircraft versus the computed DRI is shown in Figure 1.

\begin{tabular}{|c|c|c|c|c|c|c|}
\hline \multirow[t]{2}{*}{ DR level } & \multicolumn{2}{|c|}{$\begin{array}{c}\mathrm{X} \\
\text { (eyeballs out, in) }\end{array}$} & \multicolumn{2}{|c|}{$\begin{array}{c}Y \\
\text { (eyeballs right, left) }\end{array}$} & \multicolumn{2}{|c|}{$\begin{array}{c}\mathrm{Z} \\
\text { (eyeballs up, down) }\end{array}$} \\
\hline & $D R_{X}<0$ & $D R_{X}>0$ & $D R_{y}<0$ & $D R_{y}>0$ & $D R_{z}<0$ & $D R_{z}>0$ \\
\hline $\begin{array}{l}\text { Very low } \\
\text { (nominal) }\end{array}$ & -22.4 & 31 & -11.8 & 11.8 & -11 & 13.1 \\
\hline $\begin{array}{l}\text { Low } \\
\text { (off-nominal) }\end{array}$ & -28 & 35 & -14 & 14 & -13.4 & 15.2 \\
\hline
\end{tabular}

Table 1. Orion Dynamic Response Limits

\begin{tabular}{|l|c|c|c|c|c|c|}
\hline \multirow{2}{*}{ DR level } & \multicolumn{2}{|c|}{$\begin{array}{c}\text { X } \\
\text { (eyeballs out, in) }\end{array}$} & \multicolumn{2}{c|}{$\begin{array}{c}\text { Y } \\
\text { (eyeballs right, left) }\end{array}$} & \multicolumn{2}{c|}{ (eyeballs up, down) } \\
\cline { 2 - 7 } & $D R_{x}<0$ & $D R_{x}>0$ & $D R_{y}<0$ & $D R_{y}>0$ & $D R_{z}<0$ & $D R_{z}>0$ \\
\hline $\begin{array}{l}\text { Low (same as } \\
\text { NASA spec) }\end{array}$ & -28 & 35 & -14 & 14 & -13.4 & 15.2 \\
\hline Moderate & -35 & 40 & -17 & 17 & -16.5 & 18 \\
\hline High Risk & -46 & 46 & -22 & 22 & -20.4 & 22.4 \\
\hline
\end{tabular}

Note that if side restraints are used, the DR levels for Y increase to -15 and +15 (Low), 20 and +20 (Moderate) and -30 and +30 (High Risk).

Table 2. Dynamic Response Limits From Brinkley, 1989.

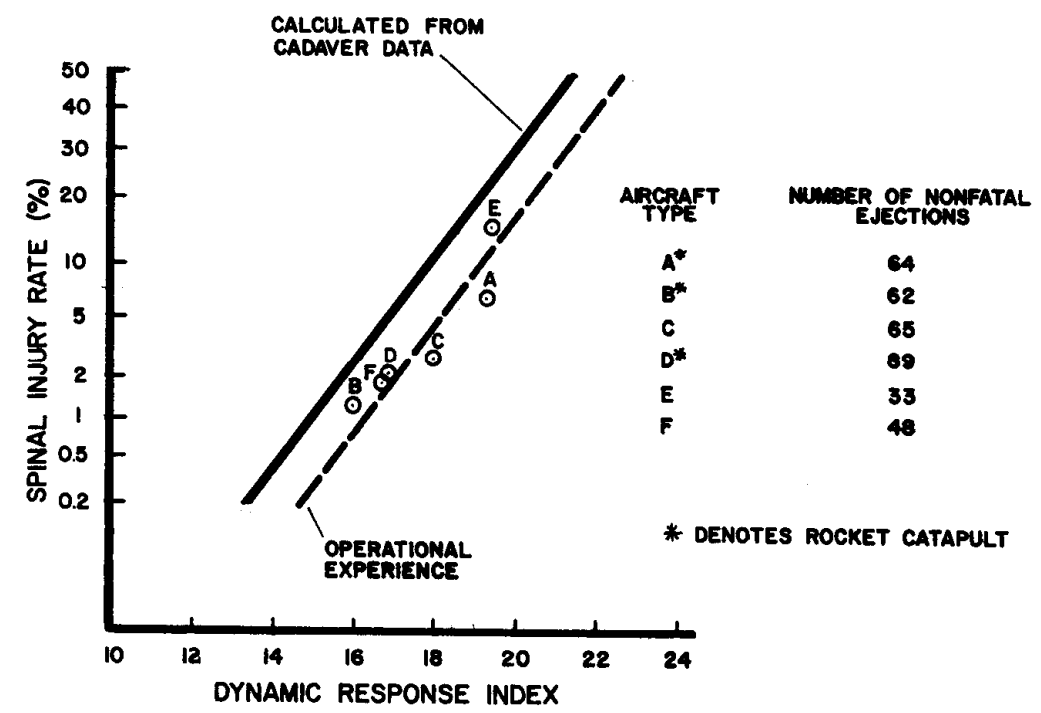

Figure 1. Spinal injury rate for operational ejections from military fighters. 
Impact tolerance studies for aerospace applications generally use modified automotive anthropomorphic dummies with an added lumbar load cell above the pelvis to physically measure the dynamic load time-history along the spine under impact conditions. Any load exceeding 1500 pounds is likely to produce spinal injuries in a 50th-percentile male.

\section{Parachute Systems}

The most common initial deceleration systems for spacecraft returning to earth from space are parachutes. Aircraft-like landing systems are the safest, but require long runways and skilled pilots, and the wings and wheels constitute about 20 percent of the vehicle weight. A parachute landing system is generally much lighter than wing systems at 3 - 6 percent of the vehicle weight, but is limited to weights less than 40,000 pounds (Sarigul-Klijn, 2003). For reliability, either backup chutes or multiple chutes are needed. For example, Mears (1993) reported that the parachute failure rate for non-heavy payloads was $0.4 \%$ or 4 out of 1000 . Although the Mercury, Gemini, and Apollo programs had some close calls with water impact landings, notably the sinking of Gus Grissom's Liberty Bell 7 Mercury capsule due to a faulty explosive hatch and the one parachute out water impact of Apollo 15 (West, 1973), there were no injuries or fatalities. Unfortunately, the space shuttle orbiter (Columbia) and the land landing Soyuz capsule have both had fatal earth entries while attempting land landings from space.

To keep the size of parachute systems reasonable, and to optimize the weight of the landing system, the terminal velocity of most parachute recovery systems is approximately 25 to $40 \mathrm{ft} / \mathrm{s}$. In addition to the terminal vertical velocity, the parachute and capsule move horizontally depending on the wind speed. Capsule landing velocities with parachute are close to typical survivable crash impact velocities for small aircraft and helicopters; therefore, one can expect that without some type of mitigation for impact loads onto land, capsules with parachutes alone are likely to produce crew injuries on land landing. The Apollo capsule was designed to impact the water with a hang angle (pitch) of 27 degrees. Since the Apollo entered the water pitched at an angle (thus giving it a rounded wedge shape), the capsule acceleration was nominally 10 G's or less for a 30 $\mathrm{ft} / \mathrm{s}$ impact (Jones, 1970). The Apollo spacecraft also had crushable ribs, and the crew seats were attached to an internal pallet with stroking energy absorbers to alleviate offnominal impacts. However, either a land landing of Apollo in an abort condition or a flat 0 -degree attitude water impact with one chute out may have resulted in occupant injuries. Since the probability of a pad abort with a land impact was considered to be low, the Apollo program accepted those risks.

With the exception of Soyuz and Apollo, there are few manned recovery systems with parachutes that can be used to assess reliability, cost, or effectiveness. Recently Cirrus, a manufacturer of small fixed wing airplanes, developed a solid-rocket-activated parachute that could be deployed in just a few seconds by the pilot in case of an emergency. Cirrus uses a 55-ft diameter single parachute to gently glide down to earth with the entire aircraft underneath. Several successful deployments have occurred since the system was made operational in 2000. 


\section{Operational Airbag Landing Systems}

Large external airbags are being considered for the Orion land landing system to reduce the landing loads and to protect the Orion capsule from damage since one of the design considerations of the Constellation Program is reusability, if practical. Internal automotive airbags are deployed in milliseconds and typically use a hot gas generator system for deployment. In contrast, deployment time for external airbag landing systems is less stringent and can often be tailored as part of the overall system design. The Orion LS ADP was responsible for test and analysis of prototype airbag (and retrorocket) landing systems suitable for Orion. Consequently, these and other airbag energy attenuating systems will be reviewed in the following subsections of this paper.

\section{Mars Airbag Systems}

The Mars Exploration Rover (MER) missions with rover payloads "Spirit" and "Opportunity" used Vectran airbags that were the same as those used in the 1997 Pathfinder mission. These airbags were inflated over several seconds using a gas generator system. The MER airbag system consisted of multi-layer spherical airbags attached together and to the MER with criss-crossed straps called tendons that resembled a loose net. Vectran is an excellent choice for the airbag fabric since it is more than twice as strong as Kevlar, performs better at cold temperatures, and is designed to survive impacts with rocks without tearing through all the layers. Extensive testing of the airbags was performed at NASA Glenn Research Center onto a simulated Mars rocky surface at the expected Mars impact velocity of approximately $60 \mathrm{ft} / \mathrm{s}$. A photograph of a system of interconnected spherical airbags set-up for testing is shown in Figure 2. Since the atmosphere of Mars is very thin, a parachute was not sufficient to slow the MER sufficiently for a safe landing even with the airbags. Thus, retrorockets were activated by a ground-sensing device approximately 50 feet above the Martian surface. The vendor that supplied the MER airbags also supplied generation 1 and 2 airbags for the NASA Langley ADP Orion test program.

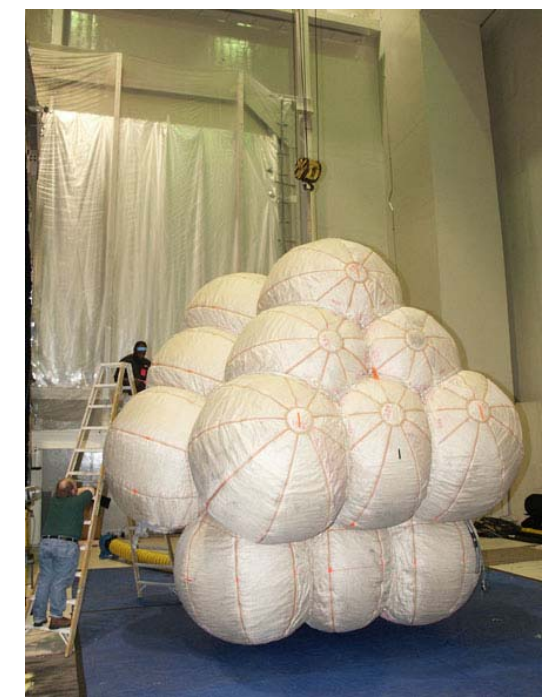

Figure 2. Airbag testing for the MER Program. 


\section{F-111 Module Airbag}

The first operational aircraft escape system that used a combination of parachutes and airbags for manned landings onto multi-terrain (land or water) was the 3,000 pound crew escape module of the F-111 fighter (Brinkley, 1968). Although the F-111 module is not a space capsule, the technology, hardware, and impact velocities are applicable. The vertical impact velocity of the F-111 module with parachute was approximately the same as is estimated for Orion; i.e., $26 \mathrm{ft} / \mathrm{s}$. Note that unlike a space capsule, the F-111 occupants in the module are seated upright and not on their backs. The F-111 airbag system consisted of a neoprene-coated nylon cloth airbag that weighed almost 3\% of the capsule's weight. Compressed air tanks were used to inflate the airbag. The airbag was located on the flat, underside of the capsule and contained blow-out plugs that were designed to tailor the amount of energy absorbed. Beginning in the 1980's and continuing through the mid-1990's, impact tests of the F-111 crew escape module onto soil were performed at the LandIR facility in support of the U.S. Air Force (Chambers, 2000). During the 15-year period of time, approximately 70 impact tests were performed of the F-111 crew module with different airbag designs. Some of the tests were conducted onto concrete and some onto a soil surface under a variety of roll, pitch, and yaw angles to represent the range of impact attitudes possible with a parachute landing.

In 1991, twelve F-111 module impact tests were conducted at LaRC. In those tests, the vertical velocity was varied from 23 to $32 \mathrm{ft} / \mathrm{s}$, while the horizontal velocity was varied from 0 to $44.5 \mathrm{ft} / \mathrm{s}$. The accelerations on the pilot and copilot seat pan were measured in the local $\mathrm{X}, \mathrm{Y}$, and $\mathrm{Z}$-directions, where $\mathrm{X}$ for a flat impact is horizontal, $\mathrm{Z}$ is positive upward, and $\mathrm{Y}$ is to the side. The acceleration to the pilot seat in the Z-direction (eyeballs down) was 15 G's. For combined vertical and longitudinal velocities, the peak accelerations in the Z-direction were typically larger than the $\mathrm{X}$ - and $\mathrm{Y}$-axis accelerations and were approximately 20 to $30 \mathrm{G}$ 's. In addition to the undesirable accelerations, the F111 parachute with airbag system was prone to produce excessive rebound velocity with undesirable tumbling as illustrated in Figure 3. For Orion, similar accelerations with the crew on its back would be more tolerable than in the F-111 with the crew seated upright. Although the F-111 airbag was modified many times, its effectiveness was marginal in reducing the impact forces to the crew inside the capsule during land landings. The F111 was retired in 1996, shortly after the last series of airbag testing was completed. Although many resources were spent on the F-111 impact attenuation system, the design was never fully satisfactory as the operational spinal injury rate at over $20 \%$ was higher than other comparable systems that used ejection seats. 

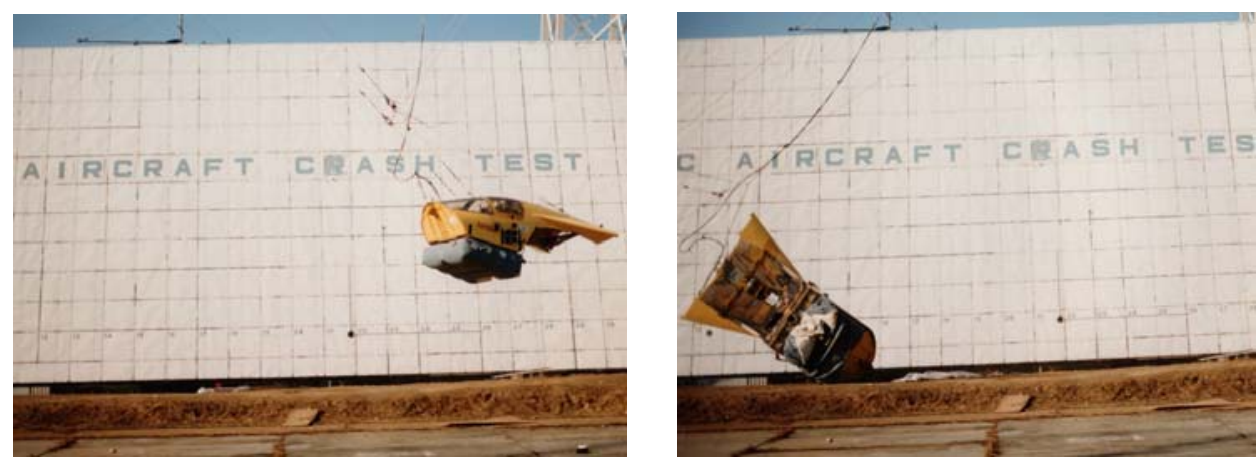

Figure 3. Photographs of an impact test of the F-111 crew escape module with airbag attenuation system.

\section{Helicopter External Airbag Systems}

Starting in the 1990's, Rafael, a company headquartered in Israel, has been developing multiple automotive-type (explosive gas-generating) airbags beneath helicopters to limit acceleration to the occupants and to limit damage to the helicopter for survivable crashes (Yosuf, et al, 2006). The US Navy has sponsored some of this development. The Rotorcraft External Airbag Protection System (REAPS) airbags are attached under the fuselage of the rotorcraft, and are designed to moderate the crash impact loads when impact either hard soil or water. A proximity sensor used to monitor the distance above the impact surface has been one of the primary problems in developing this technology. Also of concern is the ability of automotive type airbags to handle the shear loads generated during landings with high horizontal velocities.

In December 2005, REAPS testing took place near Phoenix, AZ using a Bell 206 rotorcraft as the test article. Two drops at impact velocities of $27-$ and $34-\mathrm{ft} / \mathrm{s}$ were conducted at a maximum gross weight of 3300 lbs. The rotorcraft was equipped with four Anthropomorphic Test Devices (ATD's); two were 50th-percentile male dummies, one was a 95th-percentile male dummy, and one was a 5th-percentile female dummy. According to the press release, the passengers were subjected to an impact of less than 25G with "absolutely no rebound and secondary impact." If the sensor and activation problems can be solved, the system shows promise for commercial helicopter use.

Recently, Boeing reported on an external airbag system to protect UAV's in the event of a crash (Bolukbasi, 2007). In the airbag development program, four airbags were attached to the skid gear of a MD 530 helicopter, which was used as the test-bed. It was determined that automotive type airbags were not suitable for the application due to the operating environment. Consequently, polyurethane coated Kevlar fabric was used.

\section{Operational Retrorocket Landing Systems}

Retrorockets have been used by the Russians from the beginning of their space program for land landings. Retrorockets on the RSC Energia Soyuz and the Chinese variant Shenzhou have proven to be weight efficient and highly reliable. Apollo-era testing 
indicated that retrorockets are also effective for water impacts. For a single-digit earth impact velocity, the crew should not experience discomfort or injury. The Russian Soyuz, now used as an alternative to the Space Shuttle to ferry astronauts to and from the International Space Station (ISS), uses a single parachute to reduce the capsule terminal sink velocity to $20-25 \mathrm{ft} / \mathrm{s}$. In case of failure, a backup parachute is deployed to reduce the velocity to about $30 \mathrm{ft} / \mathrm{s}$. During descent, the heatshield is dropped and from four to six solid propellant retrorockets are fired depending on the parachute terminal velocity. The retrorockets are fired at a height of less than 3 feet above the ground (measured by a Cesium 137 altimeter) and lower the sink velocity to less than $10 \mathrm{ft} / \mathrm{s}$. Instead of a stroking pallet that was used in Apollo and that is now proposed for Orion, individual stroking seats are used. Each seat is supine and is pivoted at the foot and has a stroking energy absorber at the head with a stroke of almost 10 inches. In addition, each of the crew has a seat insert that is custom molded to his body. A diagram showing the SoyuzTMA seating systems is shown in Figure 4.

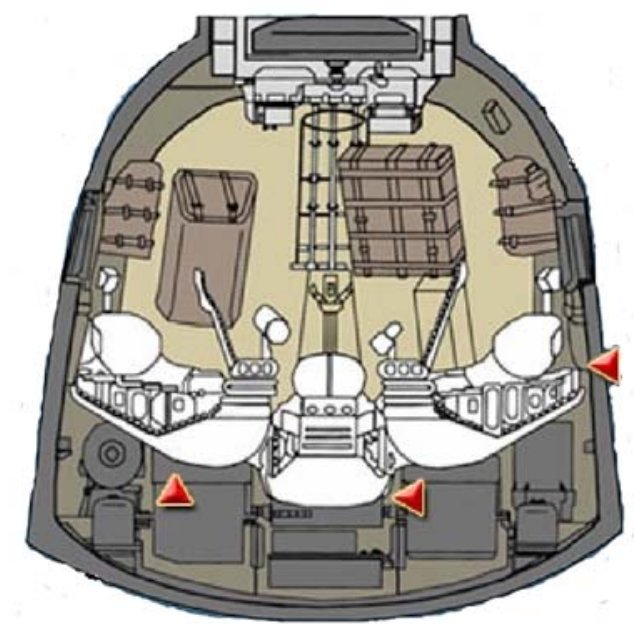

Figure 4. Soyuz TMA capsule showing seating arrangements (arrows point to seats).

A consultant report (Oberg, 1997) assessed the Soyuz landing safety using as sources the Russian press and interviews of cosmonauts, Russian officials, and Russian journalists. The report lists known landing anomalies for over 200 landings during the last 30 years. Soyuz has experienced a number of ballistic "high-G" entries in which the landing deviated from the target by over 100 miles. The Soyuz capsule on landing is not stable and tends to topple over on the side, which makes evacuation of a sick or injured astronaut during an emergency quite difficult. High horizontal winds aggravate the landing impact, both stability and resultant accelerations. A recovery operation of a Soyuz landing is shown in Figure 5. 


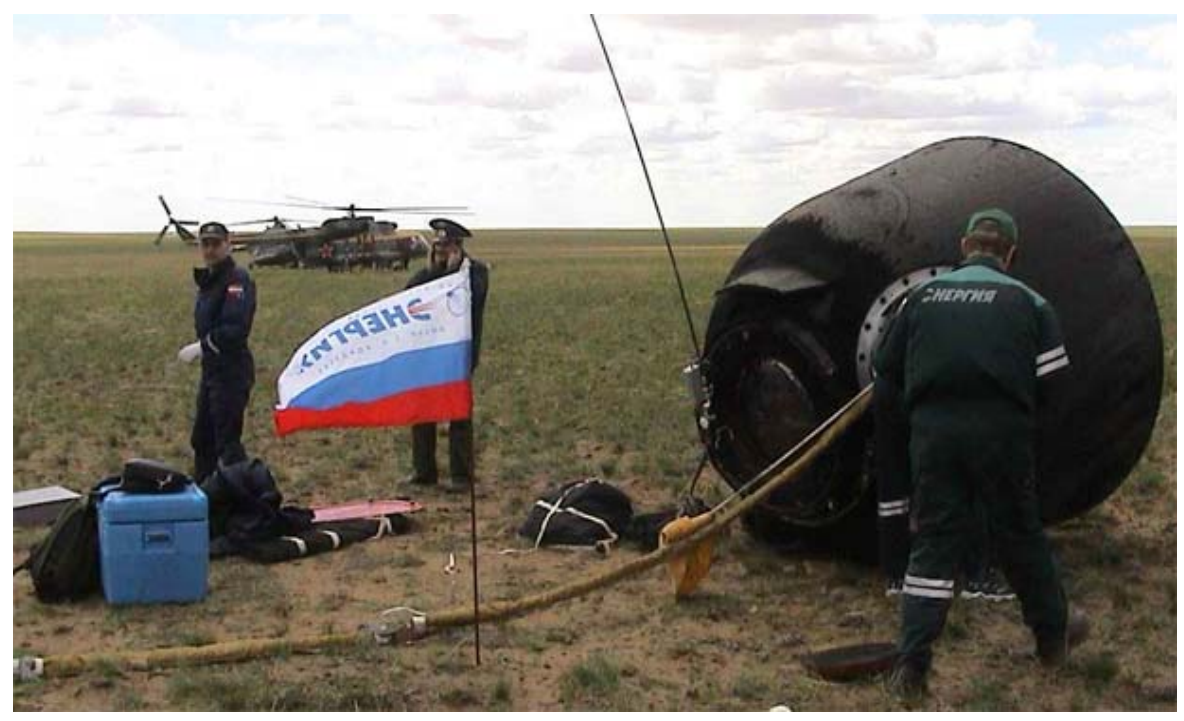

Figure 5. Recovery of a Soyuz capsule. Note the capsule is on its side.

Other non-man-rated parachute delivery systems, such as those used by the military to deliver cargo, incorporate a confluence-mounted retrorocket. With this system, the retrorocket is deployed with the parachute and is suspended below the parachute above the capsule (See Figure 6). Such a system was considered for the Constellation Program Orion capsule by the prime contractor, but was rejected due to reliability concerns regarding entanglement of the retrorocket during parachute deployment.

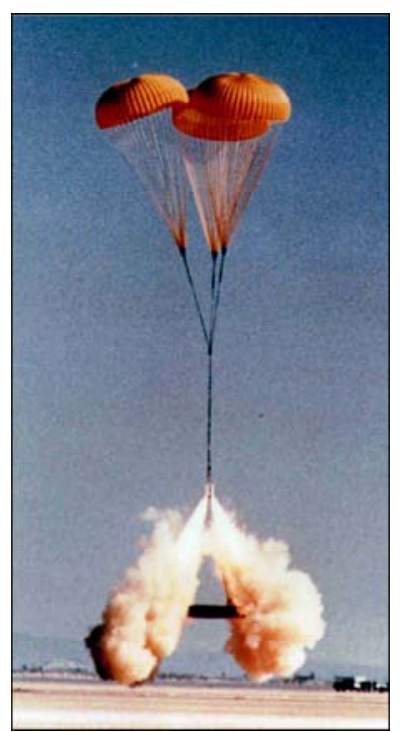

Figure 6. Confluence retrorocket system showing rocket blast just before impact. 


\section{Apollo Experience}

Apollo data were investigated to assess options, relative costs, and benefits for the design of a safe Orion landing system. Orion is larger than Apollo, but the shape can be scaled geometrically. Although the structure of Orion will be quite different, the many tests and analyses performed for Apollo landings are well worth re-examining. Thus, this report will summarize the tests and analyses that were conducted by the Apollo designers for the Command Module (CM) landings on both water (McGehee, et al, 1959; and Benson, 1966) and land (McCullough, et al, 1972). A great deal of work was performed in the 1960's, both in full- and sub-scale testing and analysis. The Apollo CM at 11,000-12,000 pounds on landing was both lighter and smaller than the current configuration for Orion at 18,000-20,000 pounds. As a first approximation, the accelerations from the Apollo tests and analyses can be applied directly to Orion as conservative benchmark data. Pictures of test facilities that were used for water and soil impact testing of full-scale Apollo boilerplates and capsules that closely resembled flight hardware are shown in Figure 7.

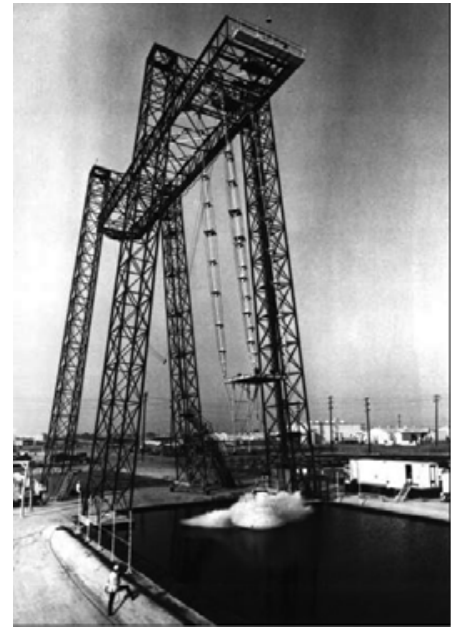

(a) North American Aviation

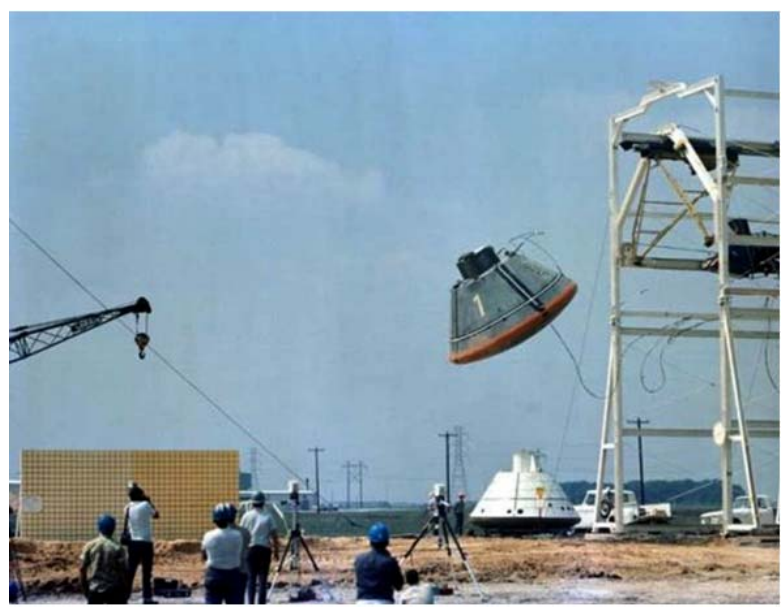

(b) Johnson Space Center

Figure 7. Apollo water impact test at North American Aviation and Apollo ground impact test at what is now Johnson Space Center.

Both test and analysis show a land landing generally produces higher accelerations for a given impact velocity than water. Soil material properties, unlike water, are highly variable with bearing pressures ranging from a few pounds-per-square-inch (psi) to hundreds of psi. Thus, for safe soil landings, either airbags or retrorockets are required to reduce the impact accelerations to less than $10 \mathrm{G}$ 's. Using the systems approach outlined with a load-limiting seat pallet for off nominal and severe impacts, the accelerations transmitted to the occupants can be reduced to survivable and hopefully non-injurious levels for all but catastrophic failures.

\section{Apollo Land Impact Test Program}

Many of the Apollo reports used scaling in which the acceleration of both the scale model and the full-size capsule scaled as one. For the acceleration to be scaled as one, the 
velocity of the scale model must be multiplied by the square root of the scaling factor. Although the Apollo capsule is similar in size to Orion, the dimensions and volumes of the Apollo and Orion do not fit the classical scaling laws. However, one can conservatively use Apollo accelerations and apply them to Orion. Scaling laws would indicate that the Orion accelerations should be slightly less than Apollo for the same impact velocity vector.

Beginning in 1967, a series of Apollo Land Impact tests were conducted at NASA Johnson Space Center (JSC), referred to during Apollo as the Manned Spacecraft Center (MSC), and at NASA Kennedy Space Center (KSC) using both "boiler plate" full-size test articles and actual spacecraft capsules. The Apollo capsule did have crushable ribs along the $+\mathrm{Z}$ direction, which is the preferred water impact orientation. These tests provided a good starting point for an estimate of Orion land impact loads without special energy attenuation or retro-rockets. During the Apollo study, 51 "boiler plate" tests were conducted and six Apollo Command Module tests were performed (McCullough, 1972). Since Apollo was "optimized" for a water impact, the Command Module (CM) had parachutes attached such that the $\mathrm{Z}$ spacecraft axis was pitched down 27.5 degrees (-27.5 degrees) with respect to the horizontal velocity. Because the CM could rotate about the "vertical," a roll angle was also specified in the report to define the orientation with respect to the velocity vector. From Figure 8, note that the CG has a Z-axis offset and that the crew's feet point in the $+Z$ direction. Thus, a 0 -degree roll will be referred to as a "toe-in" impact orientation (see Figure 8). When compared to Apollo, the Orion $+\mathrm{Z}$ axis is opposite. If the CM in Figure 8 should roll 180 degrees about the vertical, then the orientation at impact would be called a 180-degree roll or "heel-in" impact.

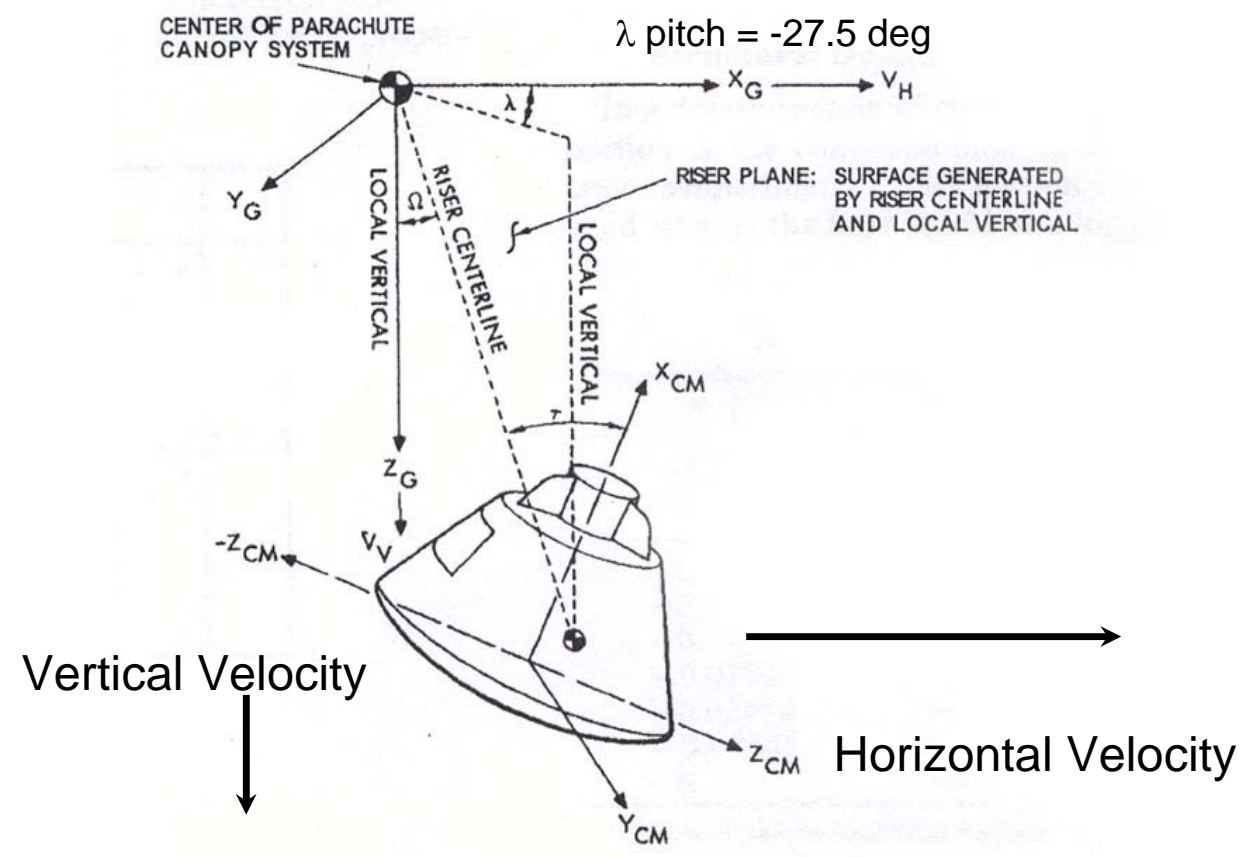

Figure 8. 0-degree roll (toe-in) and -27.5 deg pitch impact of Apollo CM into soil. The Apollo $+Z$ axis points away from the feet while the Orion $+Z$ axis points out of the head. 
A study of impact forces and moments indicated that the "toe-in" impacts were more stable. As expected in the test series, the CM for the toe-in impact did not tip over or tumble as often as for a heel-in impact. However, the toe-in impact with a pitch down does cause a considerable acceleration along the $-\mathrm{Z}$ direction. The resulting acceleration to the crew produced a large force along the spine, which compresses the spine and can lead to spinal vertebral fractures. However, the tolerance for an acceleration along the spine ( Apollo $-\mathrm{Gz}$ or eyeballs down) is about half that in the $+\mathrm{Gx}$ direction (eyeballs in).

Although peak accelerations are not the best indicator of possible injuries, they can be used as a conservative estimate of human tolerance. Information listed in Table 3 from McCullough for Apollo capsule impacts onto soil and shallow water at KSC can be used to estimate Orion impacts. For the Apollo cases shown, the vertical velocities are all very high when compared to the Orion estimated $25 \mathrm{ft} / \mathrm{s}$ vertical impact velocity under parachute. Furthermore, the critical accelerations along the spine are typically relatively high with values up to $28 \mathrm{G}$, especially for the 0-degree roll (toe-in) conditions. Only the organic muck impact at 180-degree roll (heel-in) had a higher $-\mathrm{Z}$ acceleration as compared with the 0 -degree test. All of the peak $+X$ accelerations were probably noninjurious, with only the 0-degree palmetto test at 40-G's near the upper non-injurious level (Eiband, 1959). Both of the shallow water tests were at low accelerations as compared to the tests onto soil.

\begin{tabular}{|l|l|l|l|l|l|l|l|}
\hline Test & Surface & $\begin{array}{l}\text { Roll, } \\
\text { deg }\end{array}$ & $\begin{array}{l}\text { Pitch, } \\
\text { deg }\end{array}$ & $\begin{array}{l}\text { Vertical } \\
\text { Vel, fps }\end{array}$ & $\begin{array}{l}\text { Horizontal } \\
\text { Vel, fps }\end{array}$ & $\begin{array}{l}\text { Peak CG } \\
+ \text { X-acc G }\end{array}$ & $\begin{array}{l}\text { Peak CG } \\
\text {-Z-acc G }\end{array}$ \\
\hline 1 & Grass & 0 & -27.5 & 39.1 & 36.5 & 19 & 22 \\
\hline 2 & Grass & 180 & -27.5 & 39.8 & 37.4 & 26 & 12 \\
\hline 3 & Palmetto & 0 & -27.5 & 37.2 & 36.4 & 25 & $\mathbf{2 8}$ \\
\hline 4 & Palmetto & 180 & -27.5 & 37.2 & 38.8 & $\mathbf{4 0} *$ & 8 \\
\hline 5 & Organic muck & 0 & -27.5 & 41.7 & 37.9 & 14 & 5 \\
\hline 6 & Organic muck & 180 & -27.5 & 41.3 & 37.1 & 23 & 20 \\
\hline 7 & Shallow water & 0 & -27.5 & 39.4 & 36.1 & 8 & 5 \\
\hline 8 & Shallow water & 180 & -27.5 & 39.9 & 38.2 & 18 & 6 \\
\hline
\end{tabular}

Table 3. Test Results from TN D-6979, Full-scale Apollo Command Module Impact Tests.

It is certainly desirable and also possible to orient the capsule on impact such that the acceleration along the spine is from the feet through the head (eyeball's down). However, the best pitch attitude for an Orion toe-in orientation needs to be studied further and simulated to assure that the capsule would slide instead of digging into the ground. Unfortunately, the pitch attitude for Apollo onto soil was not optimized since the capsule was rigged to have a large negative pitch with respect to the $+\mathrm{Z}$ axis to make the nominal water impact as soft as possible, and earth impacts would only occur if the wind during a launch abort caused the capsule to be blown back onto the land near the pad. 
Fortunately, some scale model testing was performed for $1 / 4$-scale Apollo capsules onto dry sand in which the pitch attitude and horizontal velocity were varied, but the vertical velocity was held constant at $30 \mathrm{ft} / \mathrm{s}$ (Benson and West, 1965). The 1/4-scale model results were scaled up to full scale using Froude scaling laws. Accelerations along the $-\mathrm{Z}$ direction (spine) for pitch angles from -27.5 (defined as toe-in) to +20 (positive defined as heel-in) are shown in Figure 9. The "D" shapes, which are colored light green, were tests for a horizontal velocity of $15 \mathrm{ft} / \mathrm{s}$. As one might expect, a large negative (toe-in) pitch produces a high acceleration along the spine. Since a limit of 10 to $15 \mathrm{G}$ 's has been set along the spine (Z-axis), almost any negative pitch exceeded the limits. The spread from 22-32 G's near -27.5 degrees compares well with the values onto grass (22 G's) and Palmetto (28 G's) reported by McCullough in Table 3 . Only the $50 \mathrm{ft} / \mathrm{s}$ extreme horizontal velocity produced a peak acceleration above 10 G's for positive heel-in pitch. However, positive heel-in pitch is generally unstable and led to some dramatic tumbling.

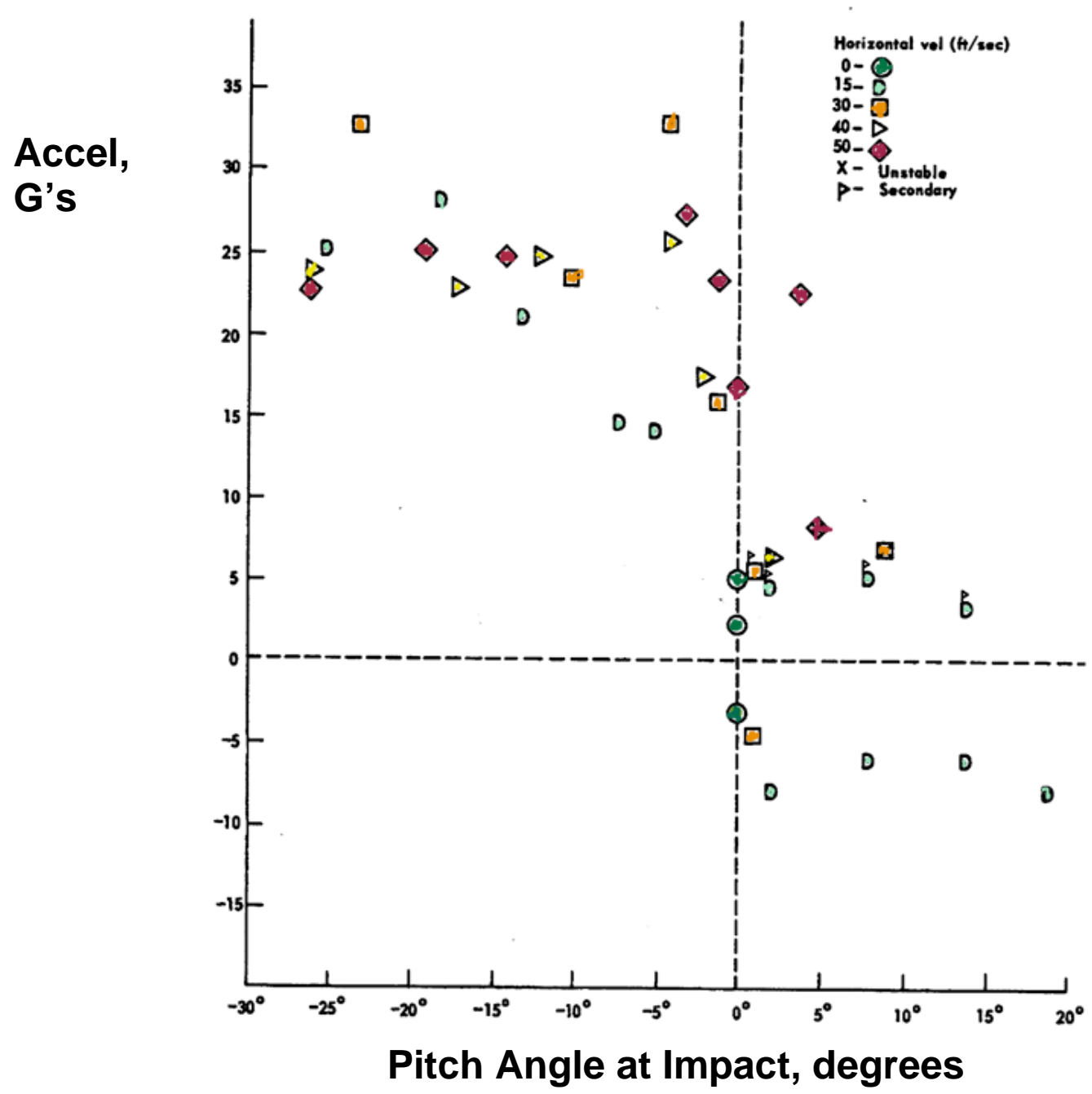

Figure 9. Peak accelerations along the Z-axis as a function of capsule pitch for sand impacts for horizontal velocities up to $50 \mathrm{ft} / \mathrm{s}$. Vertical velocity was constant at $30 \mathrm{ft} / \mathrm{s}$. 


\section{Apollo Water Landing Test Data and Analysis}

The Apollo Command Module was designed for water landings. Accelerations for water impact are lower because the stopping distance is much longer than for land landing impacts. Many studies were performed using both scaled and full-scale capsules and "boilerplates" comparing test data to analysis (Wilkerson, 1967; and Stubbs, 1967). From test and analyses performed in the 1960's, it was apparent that if the Apollo capsule was properly pitched for a water landing, the resultant acceleration to the crew could be kept at 10 - 15 G's, or below. The Apollo capsule was rigged onto the parachute riser at a pitch-down attitude of approximately -27 degrees. Figure 10 shows the maximum Xand Z-accelerations for impact tests of $1 / 4$-scale capsules (scaled to full-scale) conducted at NASA Langley by Stubbs at approximately $30-32 \mathrm{ft} / \mathrm{s}$ impact velocity into water. The pitch and the horizontal velocity were both varied for this 0-roll (toe-in) configuration. Results for a nominal pitch of -27.5 degrees is shown by the red arrows with a maximum X-direction acceleration (eyeballs in) less than $10 \mathrm{G}$ 's and a maximum Z-acceleration (eyeballs down) less than 5 G's. Solid black symbols were used to indicate those unstable cases at high horizontal velocity where the capsule flipped over in the water. In water, the heel-in 180-degree roll is more stable than the toe-in 0-roll, which is opposite to land where the 180-degree roll is less stable and leads to tumbling. Also notice that the horizontal velocity has very little effect on the level of the maximum accelerations for a given pitch.
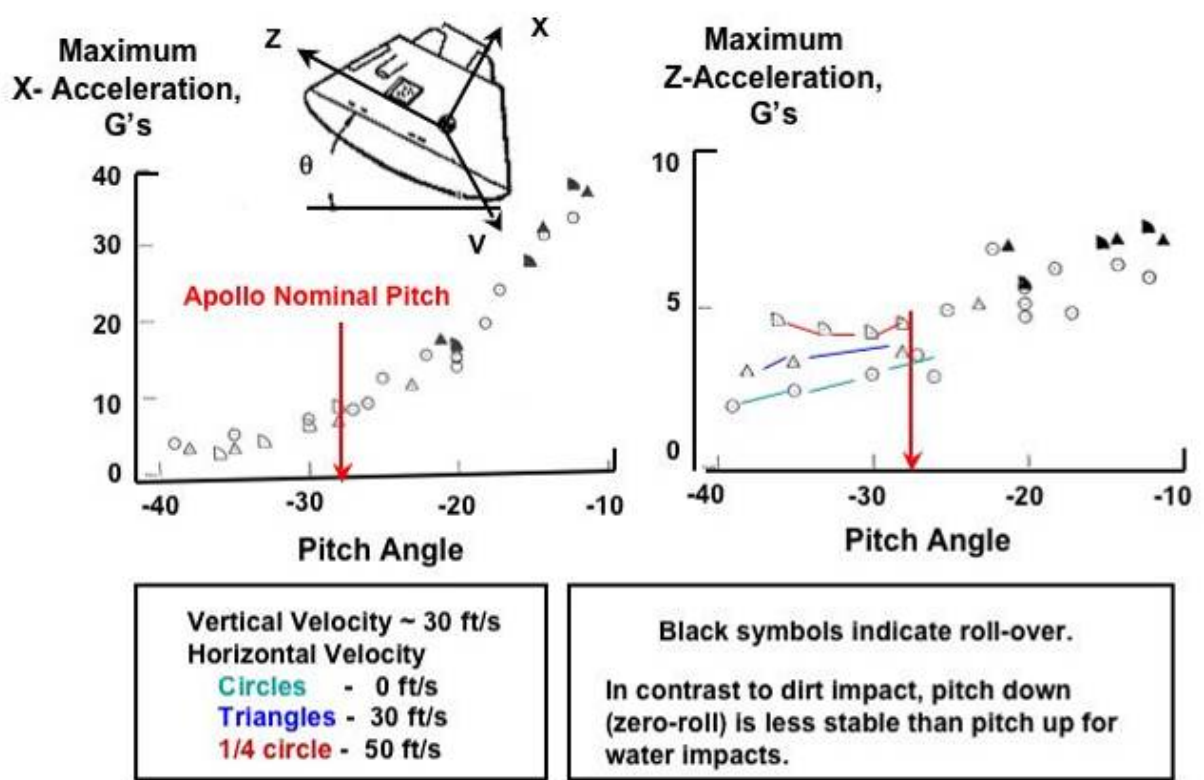

Black symbols indicate roll-over.

In contrast to dirt impact, pitch down

(zero-roli) is less stable than pitch up for water impacts.

Data from NASA TN D-3980

Figure 10. Accelerations for approximately $30 \mathrm{ft} / \mathrm{s}$ vertical Apollo water impact versus pitch angle. Zero roll, feet pointing in $-Z$ direction.

A summary of test data for simulated Apollo Command Module impact tests into water at negative pitch angles from 0 to 47 degrees is shown in Figure 11 (Wilkerson, 1967) with 
different pitch angles shown by colored symbols. The red circles correspond to small pitch angles, which produce higher maximum accelerations, while the diamond and triangles are for the larger pitch angles, which produce much lower accelerations. The box at the lower right shows that high horizontal velocities (35-47 ft/s) do not produce high accelerations as long as the vehicle pitch angle is also large.

\section{Maximum CG Acceleration, G's}

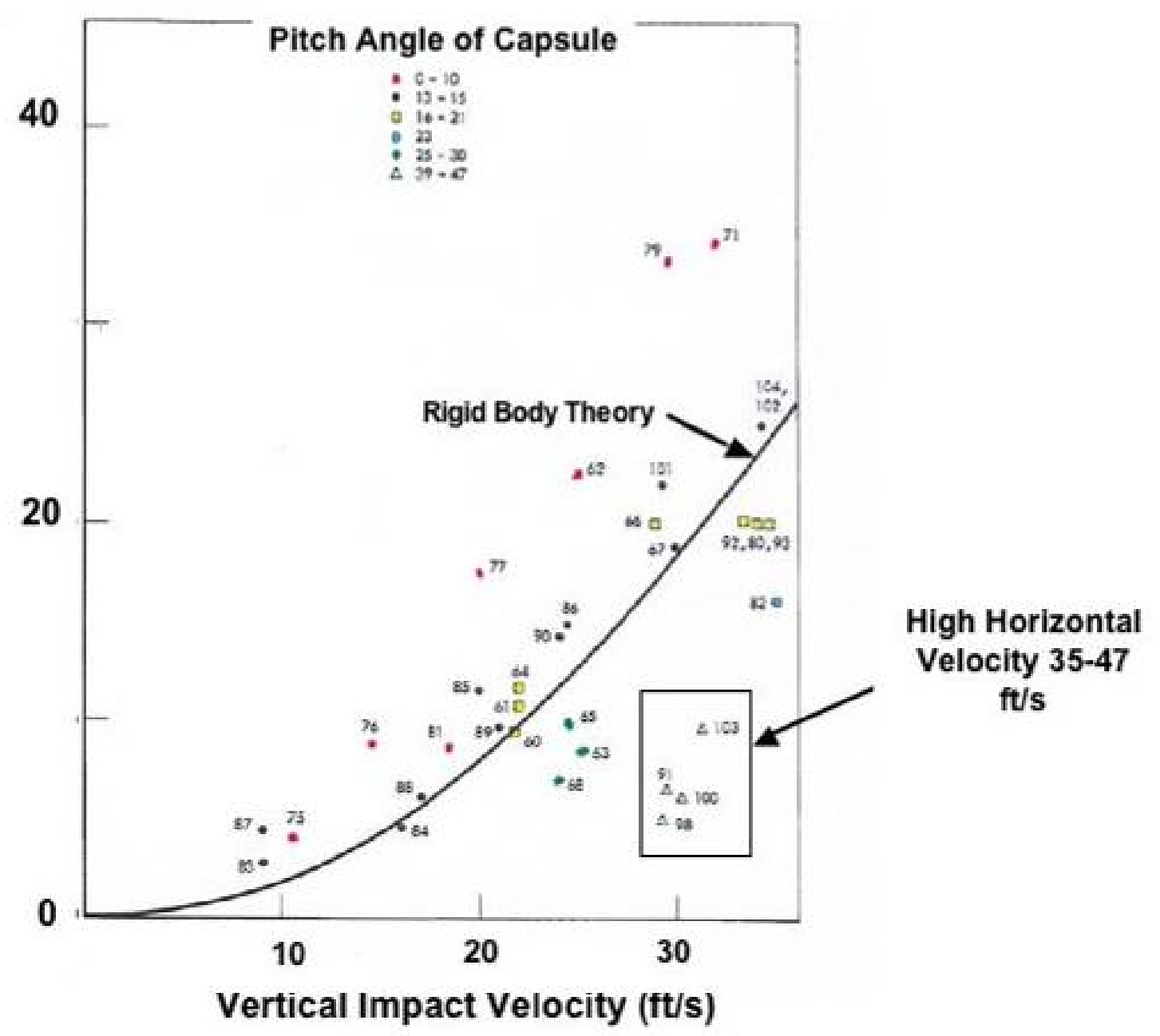

Figure 11. Test data (test number in parentheses) relating vertical impact velocity with maximum CG acceleration for different contact angles into water.

Figure 12 presents a summary of both analysis and test data for Apollo impacts into water with velocities ranging from 15 to $45 \mathrm{ft} / \mathrm{s}$. The Apollo envelope, provides the boundary of acceptable load conditions for the crew. The nominal impact velocity for Apollo and Orion are shown in red and green, respectively. From Figure 9, the resultant CG acceleration for a 27-degree contact angle, which is the angle between the water surface and the Z-axis, at $30 \mathrm{ft} / \mathrm{s}$ impact velocity is only $10 \mathrm{G}$ 's (see box). For simplicity, the crew are assumed to be aligned head-to-feet with the velocity vector with motion only in 
the $\mathrm{X}-\mathrm{Z}$ plane. In this orientation, the acceleration component in the $+\mathrm{X}$-direction (eyeballs in) is 8.9 G's, while the maximum acceleration is only $4.6 \mathrm{G}$ 's in the Zdirection (eyeballs down). These accelerations should be well tolerated. One undesirable aspect of the Apollo water landing was that the capsule was not designed to be actively rolled to provide an optimum orientation with respect to the crew. One would prefer the maximum Z-acceleration to be eyeballs down, instead of eyeballs up. Obtaining the proper roll orientation at impact is even more important for land landings, especially if the retrorockets (or other active attenuation) should fail. Since the Orion is larger and heavier than the Apollo, the data given in Figure 12 can be scaled to find the expected Orion water impact accelerations. The weight of the Apollo assumed for the curves, shown in Figure 12, was 10,400 pounds. For larger Apollo landing weights, one should take the ratio of 10,400 lbs/actual weight and scale the accelerations shown. Also, Orion's diameter is approximately 1.27 times the diameter of Apollo. For the Apollo accelerations to apply to the larger Orion, one could multiply the Apollo velocities by the square root of the scaling dimension (1.12) to get the equivalent Orion velocity. Or, one can conservatively use the Apollo accelerations for Orion "as-is" until further testing and analysis is performed.

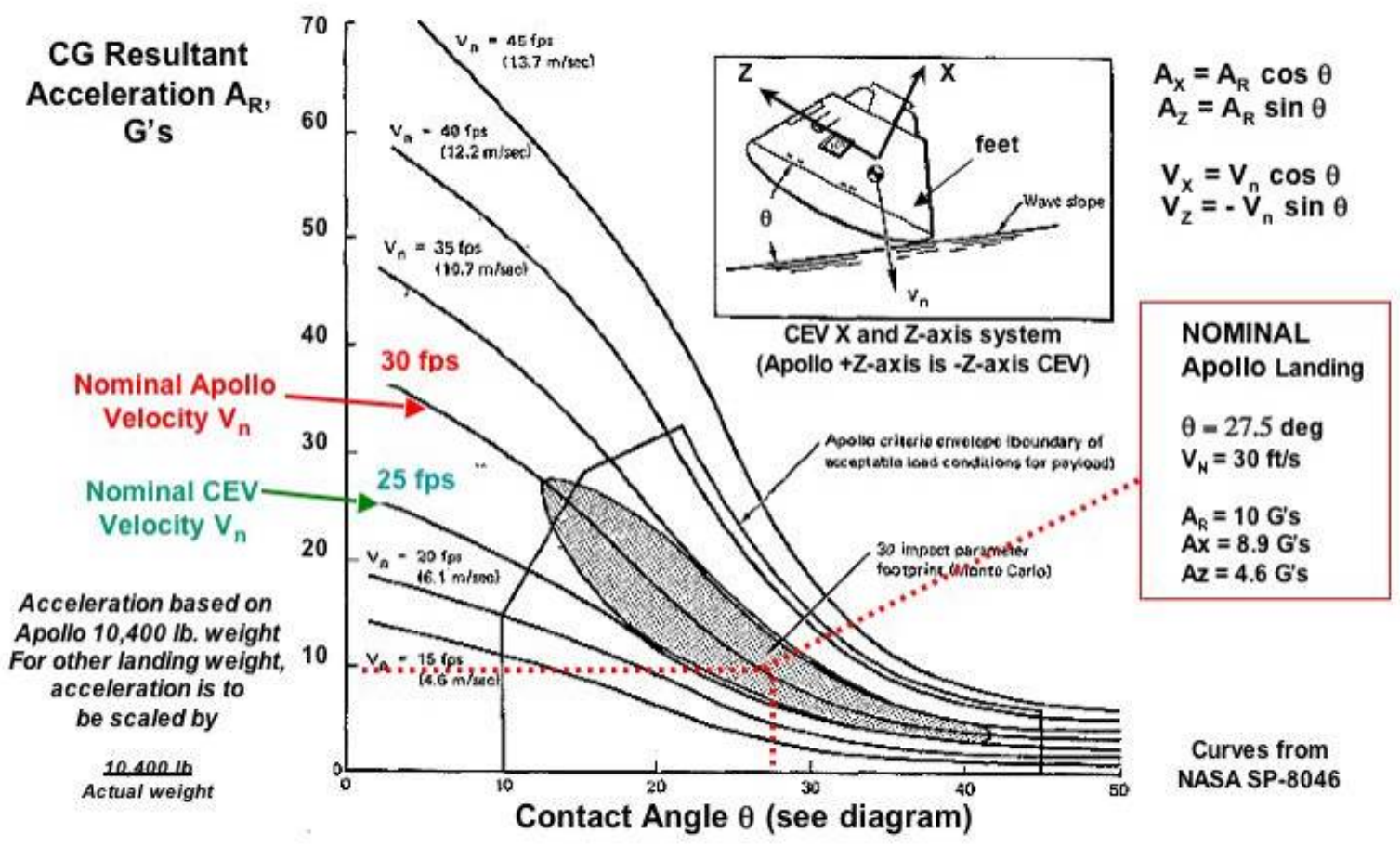

Figure 12. Resultant CG acceleration as a function of velocity and contact angle for Apollo water impact.

Apollo Land versus Water Impact

An attempt was made to compare the maximum acceleration components (X- and Zdirections) for Apollo impact tests into water with Apollo impacts onto soil for the same 
impact conditions. Although Apollo engineers performed hundreds of impact tests, data time histories were not reported for many of the tests. To perform good comparisons, the time histories need to be compared. In addition to the maximum acceleration recorded, the durations must be analyzed. Also, the Brinkley dynamic response index, which provides a good indication of probability of injury, requires complete acceleration time histories at the seat location for the X-, Y-, and Z-directions. However, the maximum accelerations shown in Table 4 do provide some relative indication of severity. Note that the $\mathrm{Y}$-axis accelerations are not considered as they were very small in magnitude. From Table 4, both X- and Z-components of acceleration for impacts into water were small and are colored green. In contrast, all of the accelerations for impacts onto soil at $32 \mathrm{ft} / \mathrm{s}$ for both the X-and Z-directions are above 40 G's. These accelerations along the X-direction may be barely tolerable; however, the accelerations along the Z-direction at the $40-50$ G's level are almost certain to produce injury. Consequently, these accelerations are colored red. The time histories for Apollo test 80 into dirt were found in McCullough (1972). These traces were scanned and digitized and input into the Brinkley computer model to obtain a maximum dynamic response. The limits for the DRI-X (eyeballs in) are 31 for a nominal Orion landing and 35 for off-nominal. The limits for DRI-Z (eyeballs down) are 13.1 for a nominal Orion landing and 15.2 for off-nominal. From Figure 13, the maximum calculated response for DRI-Z is 15.5, which is above the maximum for an off-nominal landing and would likely produce a moderate probability of injury.

\begin{tabular}{|c|c|c|c|c|c|c|c|c|}
\hline & \multicolumn{3}{|c|}{ Velocity } & \multicolumn{3}{|c|}{ Water Impact } & \multicolumn{3}{c|}{ Soil Impact } \\
\hline $\begin{array}{c}\text { Pitch } \\
\text { (down } \\
\text { ) }\end{array}$ & $\begin{array}{c}\text { Hori } \\
\mathbf{Z}\end{array}$ & Vert & Test & $\begin{array}{l}\text { Max } \\
\text { Acc } \\
\text { X }\end{array}$ & $\begin{array}{c}\text { Max } \\
\text { Acc } \\
\text { Z }\end{array}$ & Test & $\begin{array}{l}\text { Max } \\
\text { Acc } \\
\text { X }\end{array}$ & $\begin{array}{l}\text { Max } \\
\text { Acc } \\
\text { Z }\end{array}$ \\
\hline-27.5 & 0 & 32 & $*$ & 8 & 3 & $80^{* *}$ & 40 & 40 \\
\hline-27.5 & 0 & 38 & $*$ & 17 & 9 & $81^{* *}$ & 50 & 50 \\
\hline-27.5 & 25 & 32 & $*$ & 9 & 3 & $16^{* *}$ & 43 & 45 \\
\hline-27.5 & 45 & 32 & $*$ & 10 & 3 & $31^{* *}$ & 30 & 50 \\
\hline$\sim-10$ & 0 & $\sim 23$ & $90^{* \star *}$ & 13.9 & 3.5 & $*$ & 29 & 14 \\
\hline
\end{tabular}

** SID 67-498

* TN D-6979 Notes - (1) Very few soil tests under $30 \mathrm{ft} / \mathrm{s}$ vertical velocity.

* TN D-6979 $\quad$ (2) Very few pitch attitude studies for soil impacts.

* TN D-3980 $\quad$ (3) Although 100's of tests performed into dirt, test matrix is sparse.

Table 4. A Comparison of Apollo Water and Soil Impacts for Similar Impact Conditions. 

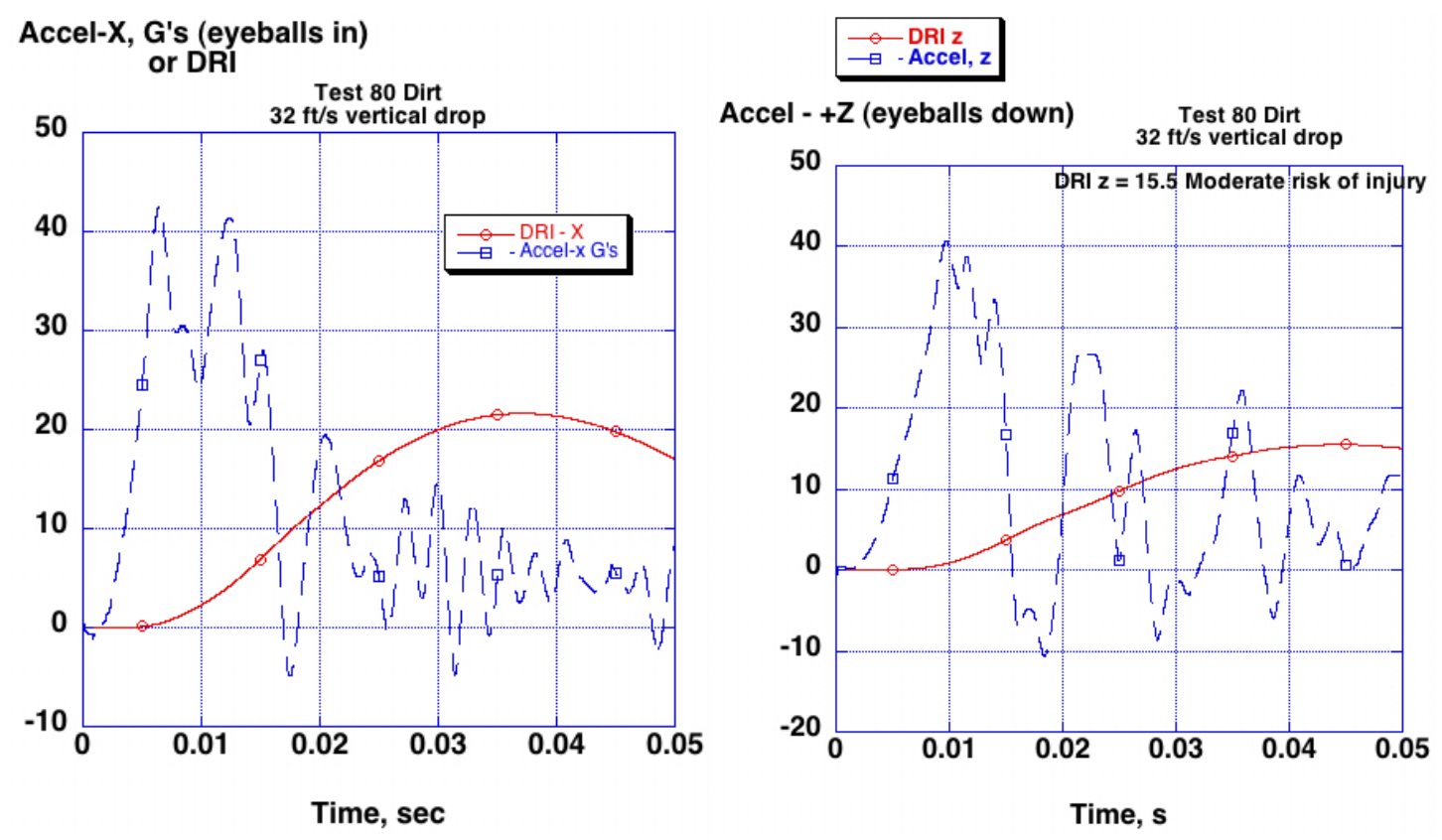

Figure 13. X-and Z-accelerations from Apollo test 80 with $32 \mathrm{ft} / \mathrm{s}$ vertical drop onto soil.

The results of computed continuous Brinkley DRI are shown as solid red lines in Figure 13. The maximum of the DRI-Z curve on the right is 15.5 , which indicates a moderate risk of injury. The maximum of the DRI-X curve, which is 22, is within nominal Orion limits (Table 1).

\section{Orion Water Landing Study}

Hundreds of tests were conducted for Apollo landings into water. Orion is larger and heavier and is expected to have a lower terminal velocity than Apollo. Using scaling, Orion should experience lower accelerations than Apollo for comparable water impacts. For pad aborts or landings into water, no additional energy dissipation is needed for nominal impacts. Relatively high horizontal velocities (up to $50 \mathrm{ft} / \mathrm{s}$ ) have been shown to have a small effect on the resultant acceleration. Transient dynamic pressures on the backside can be significant for high horizontal velocities. Dynamic simulations in the design phase can be used to size the structure to assure high pressure loadings do not cause any structure damage that might cause leakage. Some additional water impact tests will be needed for Orion boilerplate capsules to correlate the scaling and analysis.

\section{Finite Element Simulations of Apollo and Orion Capsule Landings}

Advances in computer technology since the 1960's have now made it possible to construct high fidelity, nonlinear, dynamic finite element simulations of the landing event, including the response of the structure and seats. The automotive industry has invested millions of dollars to improve computer analysis and testing techniques for crash scenarios. In addition to the airframe structure, airbags, energy absorbing material, foams, honeycomb, crushable structure, seats, and even ATD's can now be modeled, 
including important strain-rate effects that were neglected in the past. Considerable research has been conducted to develop human injury criteria for impact. Better analysis means less testing is required. Once validated with test data, the computer codes can greatly influence the final design.

New capabilities of dynamic finite element codes such as LS-DYNA (Hallquist, 2006) and other spin-offs of publicly developed DYNA3D continue to be developed. These codes can simulate ballistic impacts and explosions, seats, occupants, full-scale automobile and airplane impacts, and fluid-structural interactions such as a capsule into water or soft soil.

Separate simulation efforts will be discussed for water landing and land landing. In the Apollo-era, finite element modeling techniques for structural impact were inadequate and testing was the method of choice for verifying system performance. Currently, during the design phase, numerical modeling is the most logical and least expensive approach to study the effects of impact on a structure. With the advent of fast inexpensive workstation computers, numerical modeling of the impact of a structure into either a hard soil or a fluid media such as water can be modeled with explicit nonlinear dynamic codes. Typically, the capsule structure and hard soil is modeled with Lagrangian meshes composed of deformable elements with associated nodes that move with the element. A fluid such as water is typically modeled using a stationary Eulerian mesh in which the fluid material flows between elements, while conserving mass, momentum, and energy. When using an Eulerian fluid solver, a portion of the air volume above the water must also be modeled with an Eulerian mesh to allow the wave to form.

Water Landing Simulations of Apollo

Various schemes are typically used to model the fluid meshes and their interaction with the structural mesh. In LS-DYNA, the meshes interact by the Arbitrary LagrangianEulerian (ALE) coupling. In the ALE formulation, the Eulerian mesh and the Lagrangian mesh are coupled through an ALE interface surface. Although the Lagrangian and Eulerian grid points are separate in the logical space, grid points on the interface surface coincide in physical space, and hence the ALE interface moves as the Lagrangian structure deforms. The deformation of the structure at the ALE interface should be relatively smooth. Note, that smoothness does not require the deformation to be small in magnitude. The LS-DYNA model of a rigid body Apollo Command Module within an Euler air and water mesh was used for the simulation and is shown in Figure 14. A relatively coarse mesh with approximately 70,000 elements is shown, but a more refined mesh with approximately 500,000 elements was also generated. In Apollo nomenclature, this orientation is called the 180-degree roll (heel-in). Orientations of -11 , and -38 degrees were also generated. 


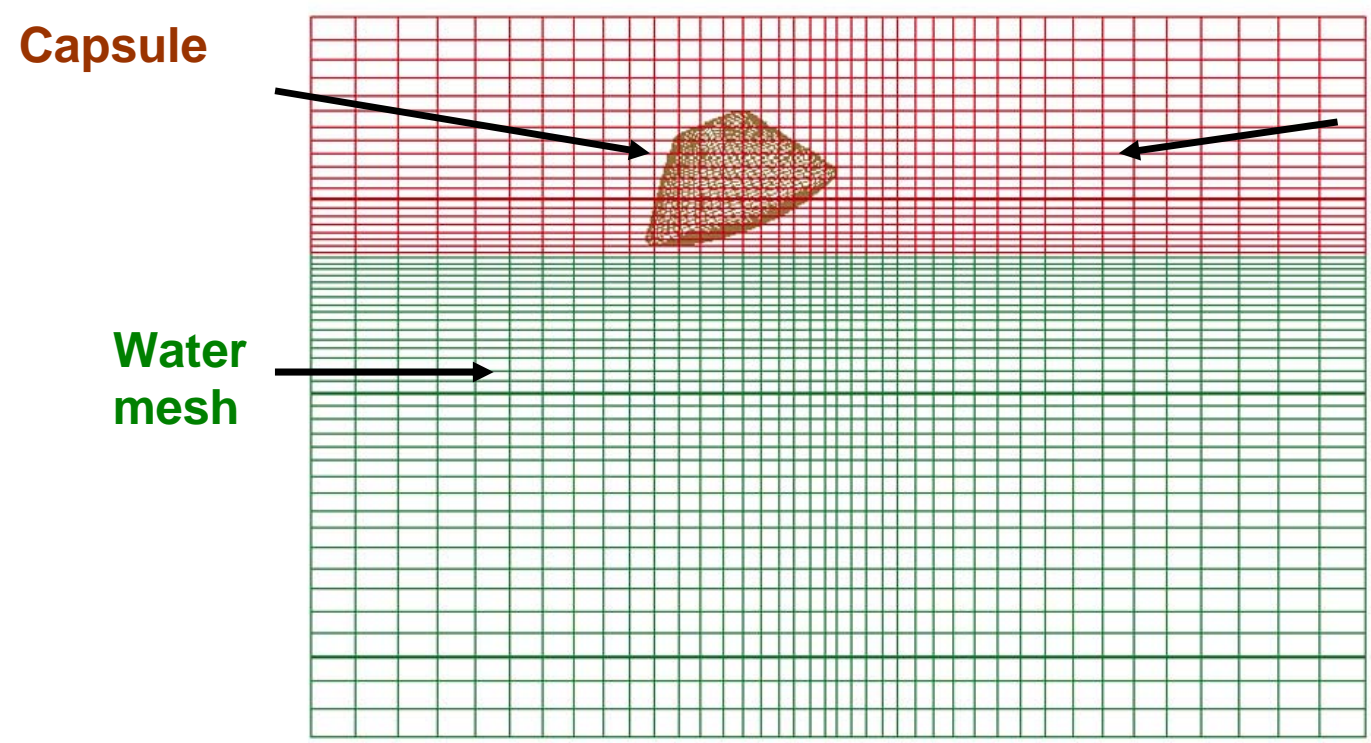

Air Mesh

Figure 14. Apollo model pitched at an angle of -21 degrees.

Initial vertical and horizontal velocities for the capsule in Figure 14 were set to $30 \mathrm{ft} / \mathrm{s}$ for correlation with a $1 / 4$-scale model test conducted by Stubbs (1967). Using the same velocity conditions, a second model was run for a pitch of -11 degrees. A comparison of the test data with analysis is shown in Table 5, where the local X-and Z-axis system is used. The LS-DYNA accelerations were filtered using a 300-Hz low-pass filter to remove the high frequency components. The resulting accelerations in the "vertical" direction are shown in Table 5 for the coarse and the fine mesh. Although the fine mesh produces peak accelerations closer to the experimental values, both meshes produce reasonable results.

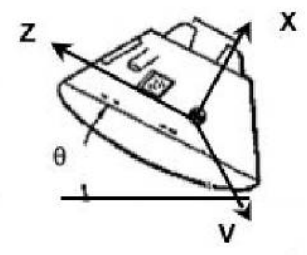

\begin{tabular}{ccccc} 
& \multicolumn{2}{c}{ Pitch -11 degrees } & \multicolumn{2}{c}{ Pitch -21 degrees } \\
& Z-Accel, G's & X-accel G's & Z-Accel, G's & X-accel G's \\
Experiment & 7.1 & 36.8 & 6.9 & 17.5 \\
Fine Mesh & 7.4 & 38.0 & 5.9 & 15.3 \\
Coarse Mesh & 8.2 & 42.1 & 10. & 26.2
\end{tabular}

Table 5. Apollo Water Impact, $30 \mathrm{ft} / \mathrm{s}$ horizontal and $30 \mathrm{ft} / \mathrm{s}$ vertical velocity Experimental Acceleration (Stubbs, 1967).

A sequence of images from the -21 degree pitch simulation is shown in Figure 15. In this case the maximum vertical acceleration occurs shortly after impact, and by 0.1 seconds, 
the vertical acceleration is approximately zero. Meanwhile, the maximum horizontal acceleration occurs around 0.04 seconds and is reduced to approximately $0.5 \mathrm{~g}$ by 0.1 seconds. Wang (2007) used LS-DYNA to simulate accelerations for a capsule with a flexible heat shield that deforms on water impact and found that the peak acceleration was greater for a flexible heat shield. This result was confirmed by experimental test data.

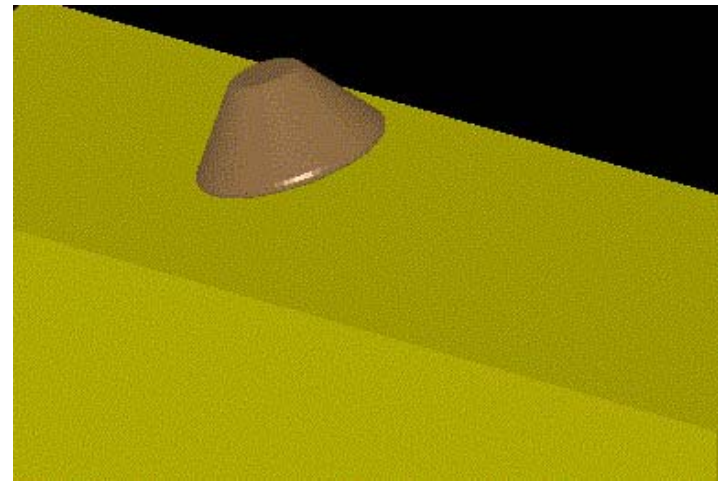

Time $=0$

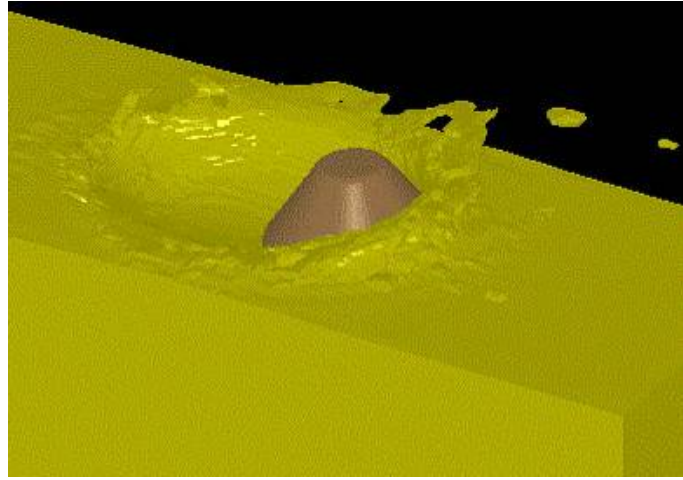

Time $=0.25 \mathrm{sec}$

Figure 15. LS-DYNA simulation for an Apollo Capsule impact into water at 21-degrees pitch for horizontal and vertical velocity components of $30 \mathrm{ft} / \mathrm{s}$.

\section{Soil Impact Simulations}

In contrast to water, which has consistent mechanical properties, the properties of soil are highly variable, especially for dynamic impacts. The microstructure of the soil, the size of the soil particles, and the void between particles or grains are very important. The bearing pressure of soft soils can be as low as $10 \mathrm{psi}$, whereas for hard soils, the bearing pressure can be hundreds of psi. In addition, the same soil can behave quite differently for dynamic impacts depending on the moisture content. The pores between the grains can be filled with either highly compressible air or with water. There are cases for dynamic loading that the media within the pores will carry the majority of the load. On the other hand, the strength of coarse soil-materials such as sand and gravel come from gravitational effects, and the materials essentially have no inherent constitutive law. For small particle size soils, such as clays, constitutive equations do apply.

In LS-DYNA, soil was modeled using the Mat5 material model, where volumetric yield is determined by a curve of pressure versus volumetric strain. The yield depends on the confining pressure. Thus, in the lab, a series of compression tests are conducted each with a higher side-wall confining pressure. Once the data are manipulated, the shear failure criteria in Mat5 has a pressure dependent failure strength of the form $A_{0}+A_{1} p$ $+\mathrm{A}_{2} \mathrm{p}^{2}$ where the A's are coefficients determined from the triaxial test and "p" is the mean stress. If the yield is low, the Mat5 model gives fluid-like behavior. In the LS-DYNA models, a soft soil must be constrained on the sides to prevent flowing under a gravity loading.

Uncertainty in soil behavior prompted the Orion LS ADP to conduct soil testing at the originally proposed western landing sites for Orion. Soil at Carson Sink in Nevada was 
typically quite soft, while the soil at Roger's Lake at Edwards Air Force Base, California was very hard. Soil samples were collected and characterized in a soils laboratory using the triaxial compression strength test to generate input for LS-DYNA Mat5 material models. In addition to the soil samples collected at each site, instrumented hemispherical penetrometers were dropped at various locations. The peak acceleration from the penetrometer's acceleration time history is used as a relative indicator of the soil strength. At this point, two soil models have been developed; one for a very soft soil that is representative of a dry unpacked sand that might be present in sand dunes, and the other for a relatively hard soil more representative of Edwards. Soft soils such as beach sand and the soils at Carson Sink near Fallon Nevada are ideal for a pure vertical velocity. A comparison of acceleration time histories from 8-in diameter 20-pound penetrometer drops from 30 inches with an LS-DYNA soft-soil model developed from data obtained from the Utah Test and Training Range (UTTR) is shown in Figure 16. The soil at UTTR was noted to yield at a pressure of about 10 psi. Notice that the analysis is approximately in the middle range of the data spread. A typical LS-DYNA penetrometer model showing the discretization is illustrated in Figure 17. Similar drops onto hard soil at Edwards produced accelerations over 150 G's.

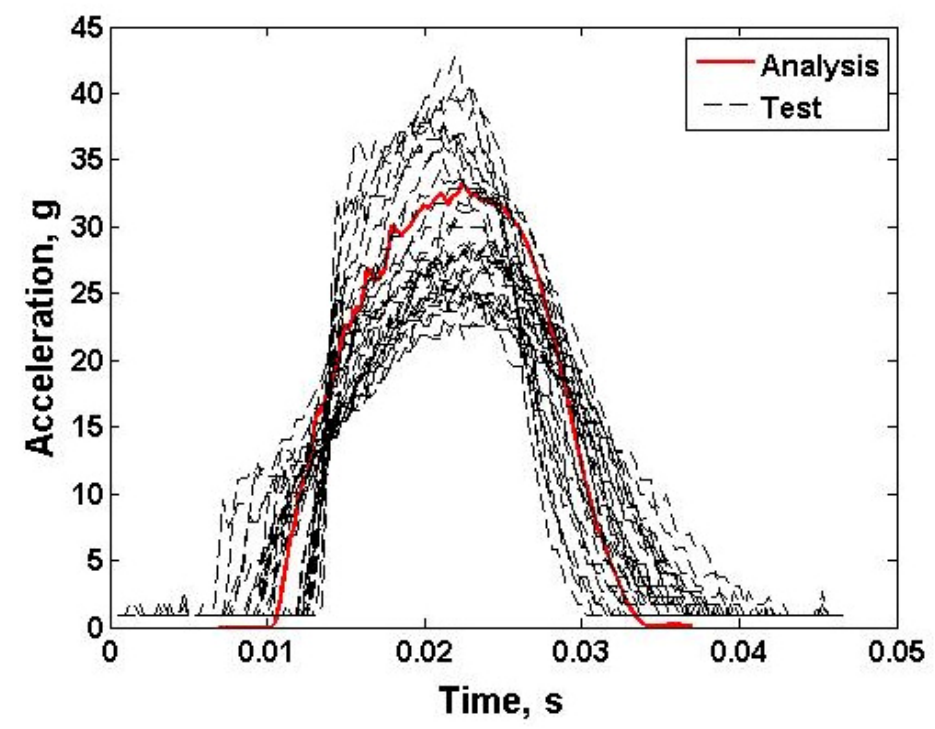

Figure 16. Accelerometer traces from a $20 \mathrm{lb}$ penetrometer dropped from 30 inches at Fallon compared with LS-DYNA model (red curve).

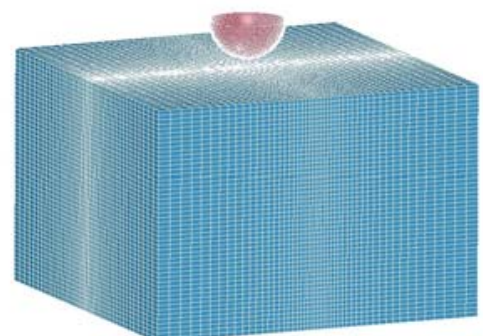

Figure 17. LS-DYNA model of 20-inch penetrometer impacting onto soil. 
In addition to the penetrometer tests, additional tests were conducted using a scaled boilerplate capsule. These tests were conducted onto soil at the LandIR facility at $58 \mathrm{ft} / \mathrm{s}$ horizontal velocity and $5 \mathrm{ft} / \mathrm{s}$ vertical velocity. For LS-DYNA modeling, the soil was assumed to be soft with a 10-psi yield. During the simulations, the rigid body capsule model skipped across the soil leaving small craters as shown in Figure 18. Although the craters were exaggerated over what was observed, the acceleration time history was comparable as shown in Figure 19.

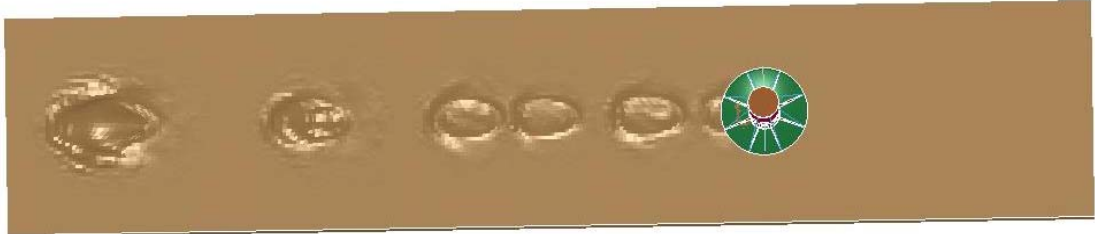

Figure 18. Scaled boilerplate capsule model impacting onto soil.
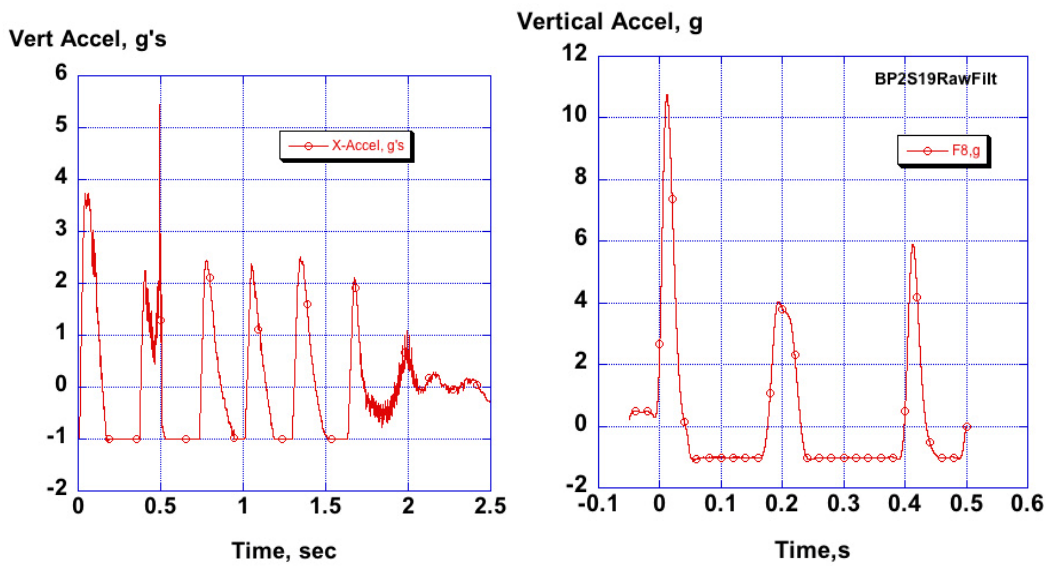

Figure 19. Accelerations of model (left) compared with initial test accelerations (right). The time is not to the same scale on the two plots.

\section{Airbag Land Landing Simulations for Orion}

During the early design phase of the Orion landing system, concerns arose about airbag performance on soft soils with relatively high horizontal winds. Of particular concern was the plowing into the soil that could either shear the airbags from the Orion structure or lead to tumbling. Although a slow turn-over of the Orion capsule is not particularly bad, severe tumbling must be avoided to protect the crew from injury and to prevent damage that would prevent reusability. To illustrate turn-over, an LS-DYNA model for a capsule weighing 16,000 pounds with six airbags landing with a horizontal velocity of 40 $\mathrm{ft} / \mathrm{s}$ and a sink speed of $25 \mathrm{ft} / \mathrm{s}$ is shown lying on its side in Figure 20. The soil model in this case was packed sand. Friction is a parameter that can be adjusted in the simulation. If the friction coefficient is lowered from 0.6 to 0.4 , then the same model did not topple. However, for a dry unpacked sand with a friction coefficient of 0.4 , the capsule model again topples for the same initial conditions. Testing will be required to verify these preliminary uncorrelated models. 


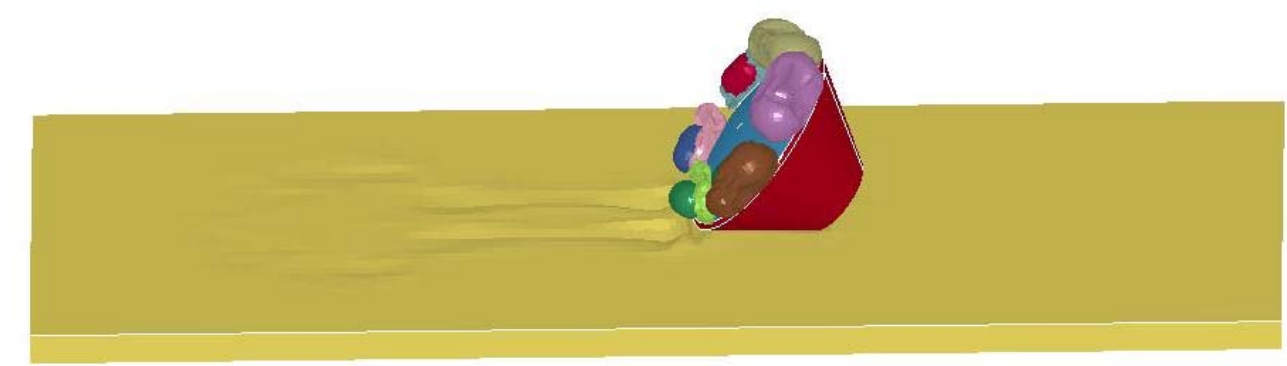

Figure 20. Capsule with airbag tumbles for $40 \mathrm{ft} / \mathrm{s}$ horizontal velocity with 0.6 friction coefficient into soft soil.

Soil material models must be carefully developed and correlated with experiments to determine the percent of dissipated and recoverable elastic energy in the soil model. The hysteresis in the unloading curve determines the energy absorbed (dissipated) by the soil, and the portion that leads to rebound of the capsule (elastic energy). Another reason why a water landing produces lower accelerations is that rebound does not occur for most impact conditions. Also, the relatively high horizontal velocities for water only have a small effect on the resultant acceleration.

\section{Passive Energy Attenuating Systems}

Although active systems such as retrorockets and airbags are effective and highly reliable, for additional protection, passive systems such as crushable structure or crushable foams should be used whenever possible. Similar to sacrificial structure at the front of an automobile, the volume beneath the pressure vessel should incorporate properly sized crushable structure such as foam or honeycomb that will reduce the acceleration to the occupants. A properly designed heatshield can also be an effective passive energy absorber. Energy absorbing devices on each seat and/or on the seat pallet are being developed for the safety of the crew, especially for off-nominal impacts.

\section{Concluding Remarks}

After retiring the Space Shuttle in 2010, NASA plans to replace the Space Shuttle orbiter with the Orion spacecraft, a capsule that is larger than the Apollo command module with room for up to six astronauts. Weight constraints are steering the current Orion design towards water landings, but the design goal is for the Orion crew to "walk away" from land landings due to a pad abort or for any other land landing. Consequently, landing systems for Orion must be designed for multi-terrain impacts. Reusability of the capsule is not a design requirement, but would be desirable.

This paper presented a survey of Apollo landing system design and testing plus an overview of previously flown landing system technologies that use parachutes. In particular, the Soyuz, which uses retrorockets in landing, and the F-111 escape module, which used a large airbag beneath the capsule, were investigated in order to extract lessons applicable for Orion. 
Finally, this paper presented representative test data generated at the NASA LandIR of developmental airbag landing systems for the Orion capsule. LS-DYNA simulations of airbag systems impacting onto soft soil and of space capsules impacting into water were presented. The primary goal of landing system research is to develop concepts to attenuate impact loads transmitted to the crew to noninjurious levels. Consequently, human tolerance to impact and Orion impact criteria were also discussed.

Safe, reliable, and effective landing system concepts can be developed to protect the Orion crew for impacts onto water, soft soil, and hard soil surfaces. The development process will be aided through the use of dynamic finite element analysis, new test data generated by ongoing experimental programs, and by incorporating lessons learned from previous landing systems. As was determined by the Apollo engineers, the simplest, lightest, and most reliable landing for a capsule such as Orion is a water landing. For a land landing, retrorockets appear to offer the lightest and most reliable active system. However, to meet reusability considerations, Orion has advanced airbag technology and has extended the state of the art. The challenge for airbag systems is to provide earth landing capability with high reliability and a low weight penalty.

\section{Acknowledgements}

The author would like to especially acknowledge the entire ADP staff at NASA Langley for providing experimental data and model results and for many discussions on Orion landing systems. In particular, special thanks go to James Corliss, Barry Bryant, Karen Lyle, Karen Jackson, Richard Boitnott, Ralph Buehrle, Robin Hardy, Lisa Jones, Sotiris Kellas, Brian Mason, Mercedes Reaves, and John Wang. James Brinkley provided information on human tolerance that was very helpful. Professor Ala Tabiei and John Wang provided water impact results. In addition, Jerry McCullough, who was the Apollo engineer in charge of soil impact tests, and Apollo astronaut, T. K. Mattingly, provided insights that could not be found in any report.

\section{References}

Benson, Harold E., "Water Impact of the Apollo Spacecraft," AIAA Journal of Spacecraft, Vol.3, No. 8, pp. 1282-1284, August 1966.

Benson, Harold E. and West, Robert E., "Results of Two One-Quarter Scale Apollo Model Impact Tests Utilizing Different Impact Attenuation Systems,” NASA TMX65129, January 1965.

Brinkley, James W., “Development of Aerospace Escape Systems,” Air University Review, July - August, 1968.

Brinkley, J. W., and Moser, S. E., "Development of Acceleration Exposure Limits for Advanced Escape Systems," AGARD CP-472, April 1989.

Bolukbasi, Akif, “Active Crash Protection Systems for UAVs,” American Helicopter Society Annual Forum 63 Proceedings, Virginia Beach, VA, May 1-3, 2007.

Chambers, J. R., "Partners in Freedom: Contributions of the Langley Research Center to 
U. S. Military Aircraft of the 1990s,” NASA SP-2000-4519, Monographs in Aerospace History Number 19, p.61-81,2000.

Eiband, A. Martin, "Human Tolerance to Rapidly Applied Accelerations: A Summary of the Literature,” NASA Memorandum 5-19-59E, June 1959.

Hallquist, John O., “LS-DYNA Theory Manual,” Livermore Software Technology Corporation, Livermore, CA, ISBN 0-9778540-0-0, March 2006.

Jones, R. H., "Landing Impact Attenuation for Non-Surface-Planing Landers,” NASA SP-8046, April 1970.

McGehee, J. R., Hathaway, M. E., and Vaughan, V. L, "Water Landing Characteristics of a Reentry Capsule,” NASA Memo 5-23-59L (1959).

McCullough, J. E., and Lands, Jr., F. F., “Apollo Command Module Land-Impact Tests,” NASA TN D-6979, October 1972.

Mears, Allen K., "Report on the Effects of Parachutes on Risk Mitigation to Third-Party Property and Individuals, Futron Corporation, prepared for Office of Commercial Space Transportation, March 1993.

Obert, James E., "Consultant Report - Soyuz Landing Safety, Soyuz Landing Historical Reliability Study,” www.jamesoberg.com/Soyuz.html, March 19, 1997.

Sarigul-Klijn, M. and Sarigul-Klign, N., "Flight Mechanics of Manned Sub-Orbital Reusable Launch Vehicles with Recommendations for Launch and Recovery,” AIAA2003-0909, September 2003.

St. Vaughan, Joshua A., Singh, Gurkirpal, Prakash, Ravi, Frisbee, Robert H. Corliss, James M., and Tutterow, Robin, "Design of a Retro Rocket Earth Landing system for the Orion Spacecraft,” 2007 IEEE Aerospace Conference, March 3-10, 2007, p1-12.

Stubbs, Sandy M., "Dynamic Model Investigation of Water Pressures and Accelerations Encountered During Landings of the Apollo Spacecraft,” NASA TND-3980, Sept.1967.

Vaughan, Victor L., Jr. and Alfaro-Bou, Emilio, "Impact Dynamics Research Facility for Full-Scale Aircraft Crash Testing.” NASA TN D-8179, 1976.

Wang, John T. and Lyle, Karen H., "Simulating Space Capsule Water Landing with Explicit Finite Element Method," $48^{\text {th }}$ AIAA Structures, Structural Dynamics, and Materials Conference Proceedings, Hawaii, 2007.

West, Robert B., “Apollo Experience Report - Earth Landing System,” NASA TN D7437, November 1973.

Wilkinson, J.P.D, “Study of Apollo Water Impact,” SID 67-498, Volume 4, May 1967.

Yosuf, V., BenMoshe, A., Noyman, Y., Gansman, Bob, and Bradney, Chris, "Rotorcraft External Airbag Protection System,” American Helicopter Society Annual Form 62 Proceedings, Phoenix, AZ, May 9-11, 2006. 